\title{
Sophia or Transvena Parasitic Wasp (suggested common name) Encarsia sophia Girault and Dodd (Insecta: Hymenoptera: Aphelinidae) ${ }^{1}$
}

\author{
Erich N. Schoeller, Vivek Kumar, Cindy L. McKenzie, and Lance S. Osborne ${ }^{2}$
}

The Featured Creatures collection provides in-depth profiles of insects, nematodes, arachnids and other organisms relevant to Florida. These profiles are intended for the use of interested laypersons with some knowledge of biology as well as academic audiences.

\section{Introduction}

Encarsia sophia Girault and Dodd (Hymenoptera: Aphelinidae) (Figure 1) is a small parasitic wasp used to control multiple whitefly pests including Trialeurodes vaporarium Westwood (greenhouse whitefly), Bemisia tabaci Gennadius (silverleaf whitefly), and T. variabilis Quaintance (papaya whitefly) (Figure 2). Because E. sophia possesses high reproductive capacity and is a prolific host-feeder, it is considered one of the most important biological control agents of whiteflies around the globe. The host-feeding capacity of Encarsia sophia on Bemisia tabaci is higher than Encarsia formosa Gahan and Eretmocerus melanoscutus Zolnerowich and Rose, two other important whitefly parasitoids, and it can kill nearly 3 times the number of whiteflies than either of these parasitoids by preying on the pest (Zang and Liu 2008).

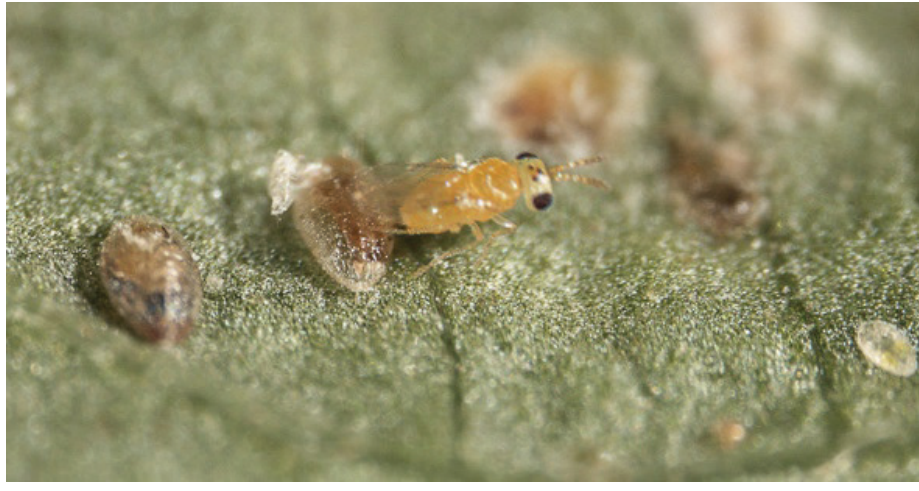

Figure 1. An adult female Encarsia sophia parasitizing a whitefly nymph.

Credits: Jack K. Clark, UC IPM

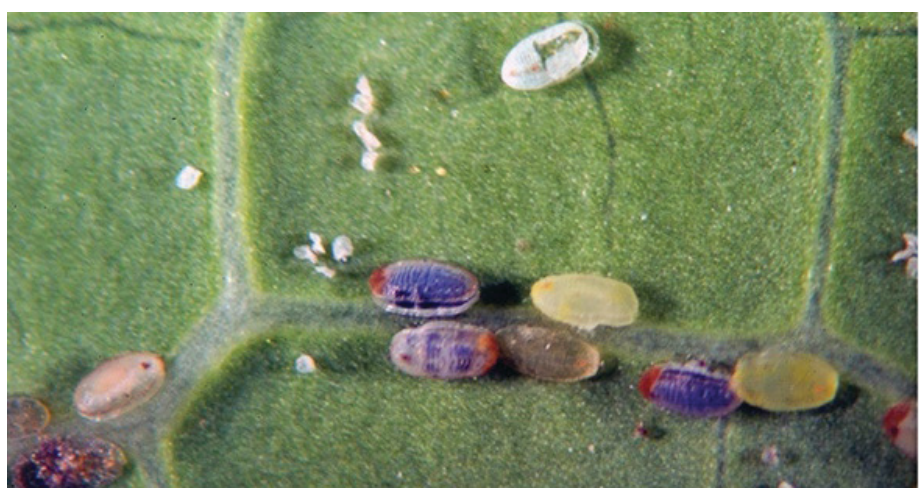

Figure 2. Papaya whitefly Trialeurodes variabilis nymphs parasitized by Encarsia sophia.

Credits: Jack K. Clark, UC IPM

1. This document is EENY-768, one of a series of the Entomology and Nematology Department, UF/IFAS Extension. Original publication date June 2021. Visit the EDIS website at https://edis.ifas.ufl.edu for the currently supported version of this publication. This document is also available on the Featured Creatures website at http://entnemdept.ufl.edu/creatures/.

2. Erich N. Schoeller, Entomology and Nematology Department; Vivek Kumar, Entomology and Nematology Department; Cindy L. McKenzie, United States Horticulture Research laboratory, ARS-USDA; and Lance S. Osborne, Entomology and Nematology Department; UF/IFAS Extension, Gainesville, FL 32611.

The Institute of Food and Agricultural Sciences (IFAS) is an Equal Opportunity Institution authorized to provide research, educational information and other services

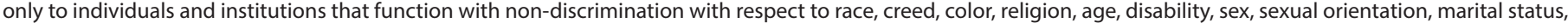

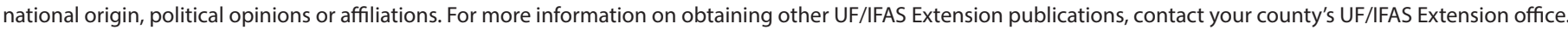
U.S. Department of Agriculture, UF/IFAS Extension Service, University of Florida, IFAS, Florida A \& M University Cooperative Extension Program, and Boards of County Commissioners Cooperating. Nick T. Place, dean for UF/IFAS Extension. 


\section{Synonymy}

Synonyms for Encarsia sophia include the following (GBIF 2017; FE 2017):

- Coccophagus Sophia Girault \& Dodd, 1915

- Prospaltella transvena Timberlake, 1926

- Encarsia transvena Timberlake, 1926

- Encarsia sublutea Silvestri, 1931

- Prospaltella sophia Compere, 1931

- Prospaltella sublutea Silvestri 1931

- Prospaltella flava Shafee, 1937

- Encarsia bemisiae Ishii, 1938

- Prospaltella bemisiae Ishii, 1938

- Encarsia flava Shafee, 1973

- Encarsia bemisiae De Santis, 1981

- Encarsia shafeei Hayat, 1986

Among different synonyms, Encarsia transvena is the most utilizedname in the literature.

\section{Distribution}

Encarsia sophia has a cosmopolitan distribution in the Old World and is considered an introduced species to the New World (Heraty and Polaszek 2000; Polaszek et al. 1992). Globally, it has been reported from Afghanistan, Algeria, Argentina, Australia, Burundi, Canary Islands, Cape Verde, China, Dominican Republic, Egypt, Ethiopia, French Polynesia, Guadeloupe, Honduras, India, Indonesia, Iran, Israel, Italy, Ivory Coast, Japan, Kenya, Malawi, Malaysia, Martinique, Mexico, Morocco, Niger, Pakistan, Philippines, Russia, Sierra Leone, Somalia, Spain, Sri Lanka, Taiwan, Thailand, Tunisia, Turkey, United States of America, and Zimbabwe (UCD 2017).

\section{Description}

Encarsia sophia is a complex of distinct cryptic species, and their performance against different whitefly species can vary depending upon the origin of the wasp population (Giordini and Baldanza 2004). Encarsia sophia is a solitary, arrhenotokous (unfertilized eggs develop into males) species, where males develop as secondary ectoparasites of female larvae. The sex ratio of E. sophia is heavily biased toward females (Gerling 1983), and both male and female are golden-yellow in color with two large black compound eyes on either side of the head. The most reliable sign of the parasitized whitefly nymph is the change in color of their "skin" (turns black) (Figure 3).

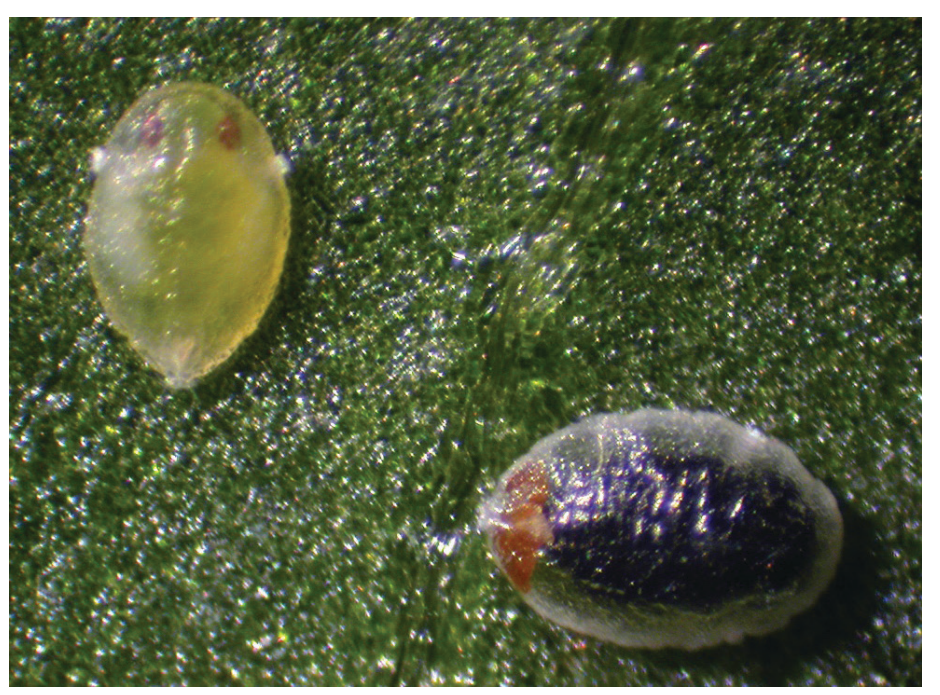

Figure 3. Change in color of parasitized (lower right) vs non-parasitized (upper left) nymphs of Bemisia tabaci.

Credits: Jack K. Clark, UC IPM

\section{Biology}

Like many Encarsia species, E. sophia is a solitary heteronomous facultative hyperparasitoid. Females develop as primary parasitoids on whitefly nymphs, while males develop as hyperparasitoids of conspecific females or other parasitoid species (Hunter and Kelly 1998). Conspecific hyperparasitism in E. sophia can occur as early as the late $2^{\text {nd }}$ instar of the female parasitoid host (Chen et al. 2013). Like E. formosa, E. sophia can develop in all B. tabaci nymphal stages, but it prefers to oviposit in older instars (third and fourth instar). Development of E. sophia can be affected by the whitefly species and the host stage parasitized. Larger host species such as T. vaporiorum yielded larger adults than those parasitizing B. tabaci (Luo and Liu 2011), which ultimately has consequences for parasitoid fitness. As an endoparasitoid, the egg, larval, and pupal stages of E. sophia occur within the host. At $25^{\circ} \mathrm{C}$, development time from egg to adult emergence can take about 12.8 days. Encarsia sophia females live for about 21.9 days, and within this period, they can lay about 79 eggs in $B$. tabaci nymphs (Zhou et al. 2010). Male development takes as little as nine days (Osborne et al. 1990). Successful emergence is evident from holes emerging adults leave in the whitefly pupal casings (Figure 4). Development can be affected by the whitefly species and the host stage parasitized. Larger host species such as T. vaporiorum yielded larger E. sophia adults than those parasitizing B. tabaci (Luo and Liu 2011), which ultimately has consequences for parasitoid fitness. In addition to parasitism, adult female E. sophia can also kill the host by host-feeding using their ovipositors to pierce the nymphs and extracting the hemolymph (Gerling 1983). Early whitefly stages are preferred for host-feeding activities. 


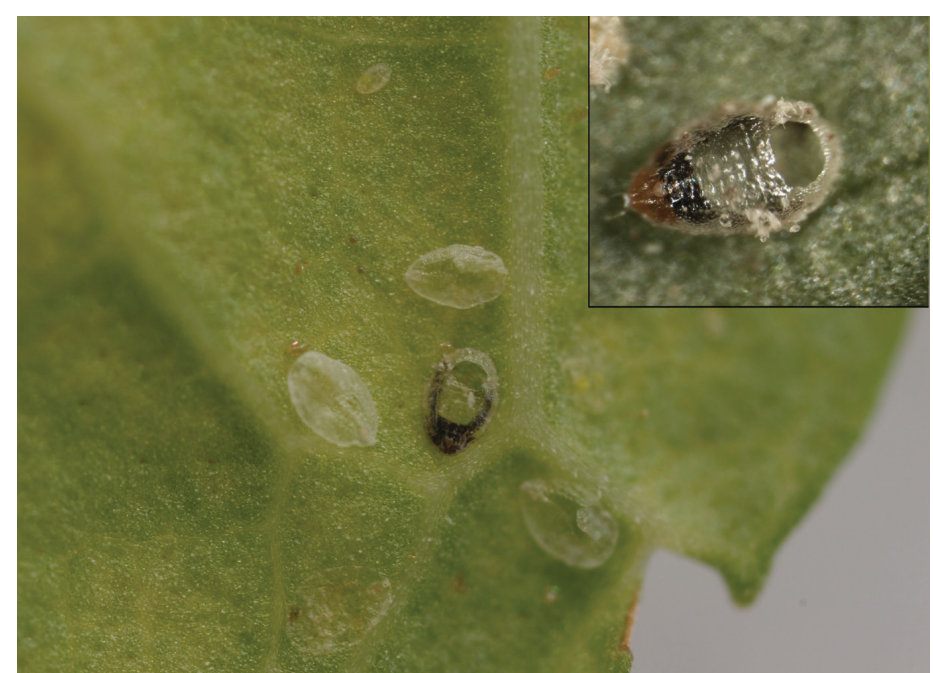

Figure 4. A hole in old whitefly pupal casing (dark colored) made by an emerged adult parasitoid.

Credits: Jack K. Clark, UC IPM

\section{Economic Importance}

Encarsia sophia has a strong dispersal and host searching ability. It is known to attack $>25$ species of whitefly species among which $B$. tabaci, and T. vaporiorum, are of great economic concern (Heraty and Polaszek 2000; Polaszek et al. 1992; Luo and Liu 2011; UCD 2017). Other organisms parasitized include: T. variabilis Quaintance (papaya whitefly), T. ricini Misra (castor bean whitefly), Acaudaleyrodes rhachipora Singh (Hayat 1989), Aleurocybotus indicus David and Subramaniam (rice whitefly), Aleurodicus dispersus Russell (spiraling whitefly), Parabemisia myricae Kuwana (bayberry whitefly) (Polaszek et al. 1992), Pealius hibisci Kotinsky (hibiscus whitefly), Aphis sacchari Zehtner (sugarcane aphid) (Timberlake 1926), and Diaphorina citri Kuwayama (Asian citrus psyllid) (Polaszek et al, 1992).

In the United States, E. sophia was released under a classical biological program for the invasive B. tabaci (MEAM1 also known as B biotype) at multiple sites during the mid-1990's (Hoelmer and Gooslby 2002). Later it was found to be established in California, Texas, Arizona, and the southern United States. Depending upon the target crop and the whitefly population level, E. sophia can be applied in greenhouses as augmentative or inoculative releases. Currently, the use of a banker plant system for their establishment and dispersal in greenhouses is actively practiced by commercial growers. The banker plant method involves placing plants with established whitefly (alternate prey host) and parasitoid colonies in the greenhouse; usually, with a whitefly that cannot establish on the target cash crop. Banker plants support parasitoid survival, multiplication, and their movement by providing the ecological infrastructure needed for their successful establishment within the protected culture. A papaya whitefly-based banker plant system for the control of $B$. tabaci on tomato has been well documented (Xiao et al. 2011). The system consists of (1) papaya as a banker plant hosting T. variabilis (papaya whitefly); (2) T. variabilis as an alternative host of E. sophia, which feed on papaya plants, but are not a pest of tomato; (3) E. sophia as the natural enemy, which exhibits strong dispersal ability and great parasitism to both $B$. tabaci and T. variabilis; and (4) B. tabaci is the target pest of tomato which is a major fresh vegetable crop (Figure 5). The system works well in regulating $B$. tabaci in tomato and poinsettia nurseries in Florida (USDA 2012). This is a vital strategy due to the difficulty in controlling $B$. tabaci populations (MED and MEAM1) with reduced susceptibility to multiple classes of chemical insecticides, as well as their status as a vector for several plant damaging viruses. It also offers organic greenhouse/nursery growers an efficient tool to reduce $B$. tabaci outbreaks in their production units.

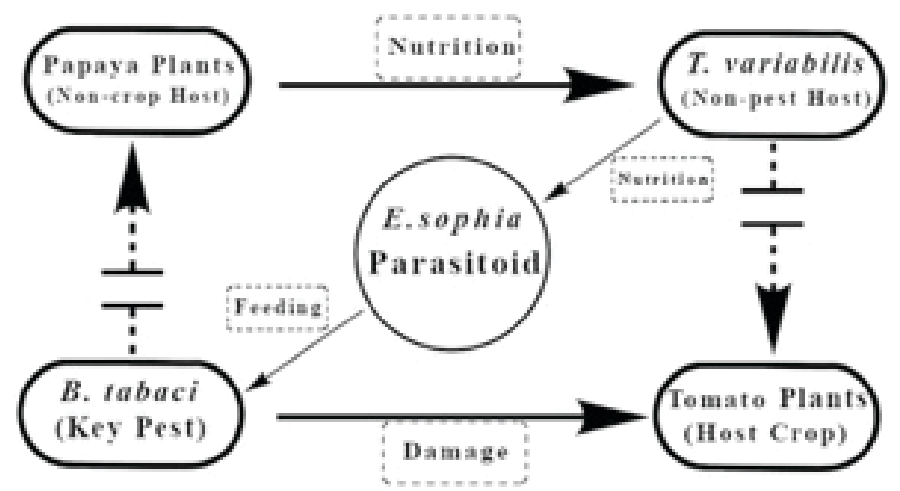

Figure 5. Schematic of an Encarsia sophia-Trialeurodes variabilis papaya banker plant system for control of Bemisia tabaci. Credits: Yingfang Xiao, University of Florida

\section{Selected References}

Chen TH, Li M, Wang JH, Zhang F, Li YX. 2013. Vulnerability window for laying male eggs and superparasitism in producing female offspring of Encarsia sophia on Bemisia tabaci B biotype. BioControl 58:27-36.

Fauna Europaea (FE). 2017. https://fauna-eu.org/cdm_dataportal/taxon/9914864c-1beb-444b-b84c-06e32b9a2ccd. 10 July 2017.

Gerling D. 1983. Observations of the biologies and interrelationships of parasites attacking the greenhouse whitefly, Trialeurodes vaporariorum (West.), in Hawaii. Proceedings of Hawaiian Entomological Society 24: 217-225.

Giorgini M,Baldanza F.2004.Species status of two populations of Encarsia sophia (Girault and Dodd) (Hymenoptera: Aphelinidae) native to different geographic areas. Biological Control 30:25-35. 
Global Biodiversity Information Facility (GBIF). 2017. http://www.gbif.org/species/1365395. 10 July 2017.

Hayat M. 1989. A revision of the species of Encarsia foerster (Hymenoptera: Aphelinidae) from India and the adjacent countries. Oriental Insects 23: 1-131.

Heraty JM, Polaszek A. 2000. Morphometric analysis and descriptions of selected species in the Encarsia strenua group (Hymenoptera: Aphelinidae). Journal of Hymenoptera Research 9: 142-169.

Hoelmer K, Goolsby J. 2002. Release, establishment and monitoring of Bemisia tabaci natural enemies in the United States. Proceedings of the 1st International Symposium on Biological Control of Arthropods, Honolulu, Hawaii, 14-18 January 2002. United States Department of Agriculture, Forest Service, Washington, USA, 2002. 58-65.

Hunter MS, Kelly SE. 1998. Hyperparasitism by an exotic autoparasitoid: secondary host selection and the window of vulnerability of conspecific and native heterospecific hosts. Entomologia Experimentalis et Applicata 89:249-259.

Luo C, Liu TX. 2011. Fitness of Encarsia sophia (Hymenoptera: Aphelinidae) parasitizing Trialeurodes vaporariorum and Bemisia tabaci (Hemiptera: Aleyrodidae). Insect Science 18:84-91.

Polaszek A, Evans GA, Bennet FD. 1992. Encarsia parasitoids of Bemisia tabaci (Hymenoptera: Aphelinidae, Homoptera: Aleyrodidae): a preliminary guide to identification. Bulletin of Entomological Research 82: 375-392.

Timberlake PH. 1926. New species of Hawaiian chalcid flies (Hymenoptera). Proceedings of the Hawaiian Entomological Society 2: 305-321.

Universal Chalcidoidea Database (UCD). 2017. Natural History Mueseum, United Kingdom. http://www.nhm. ac.uk/our-science/data/chalcidoids/database/detail.dsml?V ALSPECIES $=$ sophia $\&$ VALDATE $=1915 \&$ FamilyCode $=$ BD $\&$ HOMCODE $=0 \&$ ValidAuthBracket $=$ true $\&$ VALGENUS $=$ Encarsia\&VALAUTHOR=\%28Girault+and+Dodd\%29\&\&l istPageURL=browseMedia\%2edsml\%3f\&tab=distribution. 7 July 2017.

United States Department of Agriculture (USDA). 2012. Banking on plants as storehouses. AgResearch Magazine 60:20-21. https://agresearchmag.ars.usda.gov/AR/ archive/2012/Sep/plants0912.pdf. July 122017.
Xiao Y, Chen J, Cantliffe D, Mckenzie C, Houben K, Osborne LS. 2011. Establishment of papaya banker plant system for parasitoid, Encarsia sophia (Hymenoptera: Aphilidae) against Bemisia tabaci (Hemiptera: Aleyrodidae) in greenhouse tomato production. Biological Control 58: 239-247.

Zang LS, Liu TX. 2008. Host feeding of three whitefly parasitoid species on Bemisia tabaci Biotype B, with implications for whitefly biological control. Entomologia Experimentalis et Applicata 127: 55-63.

Zhou CQ, Li YX, Liu TX, Zhang F, Luo C. 2010. Development and morphology of female immature of Encarsia sophia and their longevity and fecundity. Chinese Journal of Biological Control 26:113-118. 